\title{
The Lived Experiences of Esophageal Cancer Patients With The Concept of Uncovering Pathways to Seeking Treatment and Follow-Up: A Qualitative Study in Arsi Zone, Oromia, Ethiopia
}

Haji Aman Deybasso ( $\square$ hajia.aman9@gmail.com )

Adama Hospital Medical college https://orcid.org/0000-0003-1441-3300

Kedir Teji Roba

Haramaya University College of Health and Medical Sciences

Tefera Belachew

Jimma University College of Public Health and Medical Sciences

\section{Research note}

Keywords: Esophageal cancer, Qualitative, lived experience, Arsi Zone, Ethiopia

Posted Date: March 22nd, 2021

DOI: https://doi.org/10.21203/rs.3.rs-322265/v1

License: (c) (i) This work is licensed under a Creative Commons Attribution 4.0 International License.

Read Full License 


\section{Abstract}

Objective: Esophageal cancer patients experience multifaceted challenges but studies often focus on the prevalence and risk factors of esophageal cancer with no documentation of the lived experiences of patients. This study aimed at exploring the lived experiences of esophageal cancer patients with the concept of uncovering pathways to seeking treatment, and follow-up.

Results:- The experience of seeking care began with self-care followed by visiting traditional healers, and hierarchical layers of health care delivery systems. The barriers to treatment follow-up were inaccessibility, unaffordability of health care services, and negative attitudes towards treatment. Patients experienced distresses linked to food intakes, treatment side effects, reduced quality of life, psychological and physical impairments. Esophageal cancer patients in this study experienced complex pathways to seeking treatment, multidimensional obstacles to treatment follow-up, and live with unbearable challenges.

\section{Introduction}

Esophageal cancer(EC) patients often experience several gastrointestinal (GI) symptoms (1), undergo invasive investigations, suffer from fear of being diagnosed with cancer(2). Furthermore, studies demonstrated multifaceted challenges including reduced physical activity, economic constraints(2,3), loss of appetite, anxiety, and depression (4).

A rapid diagnose and treatment document prepared by world cancer care in England suggested that EC patients should be diagnosed within 28 days of the first symptoms and treated as early as possible(5). Nonetheless, patients with cancer and other chronic diseases experience a delay in seeking treatment, multiple pathways to diagnoses, and treatment before receiving the final diagnosis of the disease conditions $(6,7)$.

The burden of cancer in Ethiopia is increasing rapidly with growing populations, and thousands of cancer patients are treated yearly at treatment centers(8). As a result, cancer patients often may seek treatments from multiple care providers and go through different pathways before they reach specialized health care centers capable of diagnosing and treating cancer (9).

Nevertheless, studies on EC in Ethiopia frequently focus on the prevalence and risk factors of esophageal cancer(10-12)with no documentation of the lived experiences of patients. The existing qualitative studies are mainly about the experiences of patients with breast and cervical cancer $(13,14)$. A study that involved health professionals from different disciplines working at Tikur Anbassa Specialized Hospital (TASH) reported that cancer patients exhibited a lack of knowledge about cancer and a negative attitude towards cancer treatment and its effectiveness(15). Using health professionals as a proxy indicator to assess patients' experiences is ineffective because health workers often do not ask patients about disease experiences during clinical consultations (16). Furthermore, the majority of cancer patients in Ethiopia are less educated to properly communicate with health professionals during clinical contacts or 
refuse to confer about their illness with health care providers(17). This study aimed at exploring the lived experiences of EC patients with the concept of uncovering pathways to seeking treatment and follow-up.

\section{Methods}

\section{Setting and study period}

The study was conducted among EC patients from Arsi Zone who attended the oncology department of Asella teaching and referral Hospital, Adama Hospital Medical College, and referred to the chemotherapy and radiotherapy center at TASH located in Addis Ababa. The study was conducted from September 01 to October 30, 2019.

\section{Study design}

A qualitative phenomenological study was conducted to explore the lived experiences of esophageal cancer patients.

\section{Recruitment strategy}

Newly diagnosed and patients who lived longer durations were purposefully recruited. The selection criteria were being radiographically and pathologically confirmed EC patients, living in Arsi Zone, and willing to take part in the study. Forty patients were communicated before data collection days by using a list of phone numbers. The first author confirmed voluntary participation, interview place, and time through a telephone call. Four patients declined to participate and two interviews were interrupted because of patients' health status. Data saturation was achieved with an interview of 25 patients (Additional file1: Figure S1).

\section{Data collection instrument and procedures}

Data were collected by one experienced and trained personnel who has no involvement in the daily care of the patients through in-depth interviews using semi-structured interview guides (Additional file: Table S1), audio recordings, and notes. The interviewers used pausing, probing, and question-rephrasing techniques to clarify respondents' ideas or questions. Redundant responses were considered saturated and removed after transcription of daily performances. New questions were added whenever an information gap was identified. The interviews lasted about 30 to 45 minutes.

\section{Data processing}

The first researcher transcribed all interviews verbatim after repeatedly listening to the recorded interviews. The transcripts were read sentence by sentence to identify text units (words, sentences, or a whole paragraph) and checked independently by the investigators for verification. Finally, the transcribed data were translated into English by qualified professionals and coded using Atlas.ti.7.0.71 version software. 


\section{Data analysis}

The meaning of ideas and concepts were discussed between the first author and two of the co-authors $(\mathrm{KT}, \mathrm{TB})$ and transformed themes into sub-themes. The thematic organization was repeatedly discussed between the authors until a consensus was reached. The findings of the study were presented using the finest illustrative quotations after checking for language and grammatical errors. The accuracy of the data was assessed by returning the transcripts to the participants (member-checking) while validity was maintained by an experienced external researcher who audited the research process and the study findings. Data transferability was preserved by describing the research background, selecting participants that have a disparity in durations of diagnoses and multiple treatment centers. Data were analyzed by the inductive thematic analysis method $(18,19)$.

\section{Results}

\section{Participants' socio-demographic Characteristics}

A total of 25 patients ( 14 males and 11 females) were interviewed. The minimum age of the patients was 28 years and the maximum was 78 years. The minimum and maximum duration since diagnoses with EC were 1.3 to 7.7 months, respectively. Twenty four (96\%) participants were from rural areas. In terms of education, close to $3 / 4^{\text {th }}$ of participants were unable to read and write. The religious and occupational distribution showed that 22(88\%) were Muslims and 23(92\%) were farmers respectively (Table 1)

\section{The theme of the study}

From the analysis of the interview, 53 codes, 8 subthemes, and four main themes were extracted. The themes were experiences of symptoms of esophageal cancer, pathways to seeking treatment and diagnosis, barriers to treatment follow-up, and challenges of survival with esophageal cancer.

\section{Experiences of symptoms of esophageal cancer}

Experiences of symptoms of EC were described as minor and severe gastrointestinal symptoms that prevent swallowing of foods. The general experiences of the patients were, "... we experienced dyspepsia, gastric fullness, vomiting, poor appetite, and nausea at early stages of illnesses. Experience of difficulty of swallowing foods and finally water appeared later after several months. Until then, we did not think that it was such a serious problem."

\section{Experience of pathways to seeking treatment and diagnose}

Few patients managed early symptoms at home by avoiding foods that caused dyspepsia, changing foods from solid to semisolid, and by antacid syrups. Then, they were treated with herbal medicines, holy water, and tonsil gland removal. The experiences were substantiated as, "... after / experienced the difficulty of swallowing foods, I went to a local healer that removed my tonsils.'[P-19] 
There was a very strong perception that pus from swollen tonsils can initiate the growth of cancer in the esophagus. Therefore, some of them had tonsillectomy by traditional healers before and after diagnosed with esophageal cancer(Additional file: Table S2).

As the symptoms failed to abate, they went to local health care providers such as clinics, health centers, drug stores, and pharmacy and district hospitals where they were treated for gastritis (Figure 1).

The median and interquartile range (IQR) time elapsed from the first symptoms of dysphagia to diagnosis was 3.6(2.7) months. One participant alleged the following to corroborate this,"... finally, they referred me to Tikur Anbassa Hospital in Addis Ababa six months after food began to stick to my chest.'[P-5]

\section{Experience of barriers to treatment follow up}

Experiences of barriers to treatment follow-up were linked to health care services, economic constraints, and attitudes towards cancer treatment. The services were reported as inaccessible and the costs for investigations were reported unaffordable. Participants were discouraged about the effectiveness of treatment while very few patients were counseled on medication side effects. They were not interested in radiotherapy. The circumstances of the patients were very worrying because," go home and wait for death" became the commonest experience. A 58 years old patient on follow-up said, "... Everyone living here including some health professionals advised me not to waste my resources. I have seen many individuals who died of the same cause. I believe it is Allah's verdict. What can I do.........? I will go to my home and wait until death comes. The commonest piece of advice for patients with such illnesses in our area is going home and waiting for death.'[P-23]

\section{Experience of challenges to survive with esophageal cancer}

Patients experienced persistent vomiting, loss of appetite or taste for foods, and trouble swallowing that resulted in weight loss and weakness. They were extremely malnourished, entirely dependent on their families, and desperate about their future. They were very anxious, depressed, and did not think they would survive more than 2 to 12 months. They experienced unexplained pain, lack of sleep, and fatigue. One of the participants said, "... I take only water and milk. It doesn't stay in my stomach. I lost a lot of weight within a few months. I am very worried. I did not sleep for a week. I am losing control over everything." [P-14]

\section{Discussion}

The study revealed important experiences including symptoms of EC, pathways to seeking treatment, barriers to treatment follow up and the lived experiences of survival with esophageal cancer. The identified experiences of EC patients in this study are similar to what Nordman et al reported as the "dimensions of patients suffering related to chronic illness" (20). 
In this study, EC patients experienced various vague gastrointestinal disturbances and advanced symptoms characterized by dysphagia and weight loss but none of the early GI disturbances were considered as the symptoms that are associated with esophageal cancer. A previous study demonstrated the experience of imprecise early symptoms among EC patients(1). Failure to associate the minor symptoms with E C maybe because of the similarities of such symptoms to non-cancer conditions at the early stages of the illness(21).

The study showed that EC patients go through multiple pathways to seeking treatment and diagnosis. As a result, participants were exposed to unsafe medications, harmful practices, and unnecessary investigation processes, and delay in diagnosing similar to the study findings in the previous studies $(2,22,23)$. Late presentations with advanced cancer became the hallmark of EC patients in Ethiopia(10,17).

The use of traditional medications and visiting hierarchical layers of health care delivery systems is not uncommon among African populations(17,24-26). The perception of herbal medication is that the products are "natural" and harmless for human health(27). However, herbal drugs can be toxic to the patients and /or cause undesirable interactions with anti-cancer drugs $(27,28)$ since the providers may not check for their safety and potency.

The unusual experience in this study was practices of tonsillectomy for preventing and treating esophageal carcinoma. Tonsillectomy is indicated for the removal of recurrent atrophied tonsils $(29,30)$. The finding may indicate pervasive misconceptions and a lack of knowledge of the pathogenesis and risk factors of EC among populations living in a study area.

Another theme identified in this study was experiences of barriers to treatment follow up. Distance from cancer treatment centers, multiple investigations, and negative attitudes were the major barriers. The finding is consistent with the study that reported triad challenges to cancer treatment and fellow up in Ethiopia (17).

In this study, experiences of survival with EC were designated as problems associated with food intakes, treatment side effects, reduced quality of life, psychological and physical impairments. The finding is in line with studies that recounted experiences of severe malnutrition, a sense of despair, and lack of psychological support among cancer patients $(1,2)$. Studies have shown that the local effect of the tumor itself, host response, hypermetabolism, impaired organ function, therapy-related symptoms, and radiation enteritis results in a high prevalence of malnutrition among patients who undergo palliative cancer care (31-33). Besides, EC patients who do not get psychological supports cannot cope with the effects of chemo-radiotherapy, dietary change, pain, sleep disturbances, and reduced quality of life(4).

\section{Conclusions}

Esophageal cancer patients in the study experienced complex pathways to treatment-seeking, multidimensional obstacles to treatment follow-up, and live with unbearable challenges. Comprehensive 
interventions that encompass accessible and affordable cancer care services, psychological support, and nutritional interventions should be integrated into the prevention and management of the esophageal cancer program.

\section{Limitations}

To the best of our knowledge, this study is the first in Ethiopia that assessed the experiences of the EC patients who attended multiple health care providers. However, it cannot be inferred to the general population because of the purposeful sampling of a small number of the study participants.

\section{Declarations}

\section{Acknowledgments}

The authors would like to thank health facilities for their enormous help in providing important information and facilitating every activity during data collection. We are very grateful to data collectors and participants who were very cooperative.

\section{Authors' Contributions}

HA designed the research conception, conducted the research, analyzed the data, and wrote the final report. KT and TB have provided advisory support during the whole research process, edited and critically evaluated the final report. All authors have read and approved the manuscript.

\section{Funding}

Not applicable

\section{Availability of data and materials}

The datasets supporting the conclusions of this article are included within the article and its additional file. The interview data is not publicly available to protect the study participants' anonymity.

\section{Ethics Approval and Consent to Participate}

Ethical permission to carry out the study was obtained from the Institutions Research Board (IRB) of Jimma University. Written consent was obtained from each respondent before data collection. Privacy and confidentiality were maintained throughout the study by ensuring that no names were known or written in the questionnaires. The recordings were performed after the participants have agreed to be recorded.

\section{Consent for publication}

Not applicable 


\section{Competing interests}

The authors declare that they have no competing interests.

\section{Authors' details}

${ }^{1}$ Jimma University, Department of Human Nutrition and Dietetics, Jimma, Ethiopia

${ }^{2}$ HaramayaUniversity, College of Health and Medical Sciences, Harar, Ethiopia

\section{Emails:}

HA: hajia.aman9@gmail.com

KTR: kedir.t.roba@gmail.com

TB: teferabelachew2@gamial.com

\section{References}

1. Humphrys E, Walter FM, Rubin G, Emery JD, Johnson M, et al. Patient symptom experience prior to a diagnosis of oesophageal or gastric cancer: a multi-methods study. BJGP Open. 2020;4(1):bjgpopen20X101001.

2. Andreassen S, Randers I, Naslund E, Stockeld D, Mattiasson A-C. Patients' experiences of living with oesophageal cancer. J Clin Nurs. $2006 ; 15(6): 685-95$.

3. Schandl A, Lagergren J, Johar A, Lagergren P. Health-related quality of life 10 years after oesophageal cancer surgery. Eur J Cancer. 2016;69:43-50.

4. Pinto E, Cavallin F, Scarpa M. Psychological support of esophageal cancer patient? J Thorac Dis. 2019 Apr;11(S5):S654-62.

5. NHS. Implementing a timed oesophago-gastric cancer diagnostic pathway. Rapid diagnostic and assessment pathways.A handbook for local health and care systemsNHS England Publishing Approval Reference: .April.2009. 000232.

6. Ku C-C, Chen C-C, Dixon S, Lin HH, Dodd PJ. Patient pathways of tuberculosis care-seeking and treatment: an individual-level analysis of National Health Insurance data in Taiwan. BMJ Glob Health. 2020;5(6):e002187.

7. Hanson CL, Osberg M, Brown J, Durham G, Chin DP. Conducting Patient-Pathway Analysis to Inform Programming of Tuberculosis Services: Methods. J Infect Dis. 2017 ;216(suppl_7):S679-85.

8. Kebede BG, Abraha A, Andersson R, Munthe C, Linderholm M, et al. Communicative challenges among physicians, patients, and family caregivers in cancer care: An exploratory qualitative study in Ethiopia. Frey R, editor. PLOS ONE. 2020 ;15(3):e0230309. 
9. Wondimagegnehu A, Hirpa S, Abaya SW, Gizaw M, Getachew S, et al. Oesophageal Cancer Magnitude and Presentation in Ethiopia [Internet]. In Review; 2019 Aug [cited 2020 Apr 11]. Available from: https://www.researchsquare.com/article/rs-4421/v1

10. Shewaye AB, Seme A. Risk factors associated with oesophageal malignancy among Ethiopian patients: a case control study. East Cent Afr J Surg. 2016;21(2):33.

11. Woreta SA, Yassin MO, Teklie SY, Getahun GM, Abubeker ZA. Upper gastrointestinal endoscopy findings at Gondar University Hospital, North-Western Ethiopia: An eight year analysis. Int J Pharm. $2015 ; 7$.

12. Bulcha G., Leon M., Gwen M, Abnet C., Sime A, Pritchett N., et al. Epidemiology of Esophageal Cancer (EC) In Oromia Region, Ethiopia 2016: A 4-Year Medical Record Review. J Glob Oncol. 2018 Sep 28;4(Supplement 2):14s-14s.

13. Begoinn M, Mathewos A, Aynalem A, Wondemagegnehu T, Moelle U, Gizaw M, et al. Cervical cancer in Ethiopia - predictors of advanced stage and prolonged time to diagnosis. Infect Agent Cancer. 2019;14(1):36.

14. Amare M. Perceptions and Coping Mechanisms Experienced by Ethiopian Breast Cancer Patients. 2016;7(04):8.

15. Haileselassie W, Mulugeta T, Tigeneh W, Kaba M, Labisso WL. The Situation of Cancer Treatment in Ethiopia: Challenges and Opportunities. J Cancer Prev. 2019;24(1):33-42.

16. Weinman J, Petrie KJ. ILLNESS PERCEPTIONS: A NEW PARADIGM FOR PSYCHOSOMATICS? Journal of Psychosomatic Research, Vol. 42, No. 2, pp. 113-116, 1997.

17. Haileselassie W, Mulugeta T, Tigeneh W, Kaba M, Labisso WL. The Situation of Cancer Treatment in Ethiopia: Challenges and Opportunities. J Cancer Prev. 2019 ;24(1):33-42.

18. Morrow R. Colaizzi's descriptive phenomenological method. The Psychologist, 28(8), 643-644.

19. Finch LP. Understanding patients' lived experiences: the interrelationship of rhetoric and hermeneutics. Nurs Philos. 2004;5(3):251-7.

20. Al Kalaldeh M, Shosha GA, Saiah N, Salameh O. Dimensions of Phenomenology in Exploring Patient's Suffering in Long-Life Illnesses: Qualitative Evidence Synthesis. J Patient Exp. 2018;5(1):43-9.

21. Solano JP, Gomes B, Higginson IJ. A Comparison of Symptom Prevalence in Far Advanced Cancer, AIDS, Heart Disease, Chronic Obstructive Pulmonary Disease and Renal Disease. J Pain Symptom Manage. 2006;31(1):58-69.

22. Blazeby JM \& Vickery CW. Quality of life in patients with cancers of the upper gastrointestinal tract. Expert Review of Anticancer Therapy (2001). 1, 269-276.

23. Branicki FJ, Law SY, Fok M, Poon RTP, Chu KM, Wong J. Quality of Life in Patients With Cancer of the Esophagus and Gastric Cardia: A Case for Palliative Resection. Arch Surg [Internet]. 1998;133(3). Available from: http://archsurg.jamanetwork.com/article.aspx?doi=10.1001/archsurg.133.3.316 
24. Anokbongo WW. The role of African traditional medicine in health-care delivery alongside modern medicine. In: Edwards S and Asfaw Z. eds. Plants used in African traditional medicine as practiced in Ethiopia and Uganda. Botany 2000: East and Central Africa. NAPRECA Monograph Series No. 5. Addis Ababa: NAPRECA \& Addis Ababa University, 1992;25-35.

25. Kassaye M. Integration of traditional medicine with modern care services. In: Abebe D. ed. Proceedings of the workshop on development and utilization of herbal remedies in Ethiopia. 1996 June 4-6; Addis Ababa: EHNRI, 1996:10-14.4.

26. Abdullahi A. Trends and Challenges of Traditional Medicine in Africa. Afr J Tradit Complement Altern Med [Internet]. 2011;8(5S). Available from:

http://www.ajol.info/index.php/ajtcam/article/view/67959

27. Abdel-Aziz SM, Aeron A, Kahil TA. Health Benefits and Possible Risks of Herbal Medicine. In: Garg N, Abdel-Aziz SM, Aeron A, editors. Microbes in Food and Health [Internet]. Cham: Springer International Publishing; 2016 [cited 2020 Nov 13]. p. 97-116. Available from: http://link.springer.com/10.1007/978-3-319-25277-3_6

28. Ben-Arye E, Samuels N, Goldstein LH, Mutafoglu K, Omran S, Schiff E, et al. Potential risks associated with traditional herbal medicine use in cancer care: A study of Middle Eastern oncology health care professionals: Risks Associated With Herbal Use. Cancer. 2016;122(4):598-610.

29. Ersözlü T, Yıldıım YS, Sarica S. Comparison of Pediatric and Adult Tonsillectomies Performed by Thermal Welding System. Int J Otolaryngol. 2013;2013:1-4.

30. Verma R, Verma RR, Verma RR. Tonsillectomy-Comparative Study of Various Techniques and Changing Trend. Indian J Otolaryngol Head Neck Surg. 2017;69(4):549-58.

31. Kumar, N.B., Kazi, A., Smith, T., Crocker, T., Yu, D.,et.al., 2010. Cancer Cachexia: Traditional Therapies and Novel Molecular Mechanism-Based Approaches to Treatment. Curr. Treat. Options Oncol. 11, 107-117. https://doi.org/10.1007/s11864-010-0127.

32. Ockenga J, Valentini L (2005) Review article: anorexia and cachexia in gastrointestinal cancer. Aliment Pharmacol Ther 22(7):583-594, Review.

33. Paccagnella A, Morassutti I, Rosti G (2011) Nutritional intervention for improving treatment tolerance in cancer patients. Curr Opin Oncol 23(4):322-330.

\section{Table}

Table1: Socio-demographic characteristics of participants, Arsi Zone, Oromia, Ethiopia, 2020

Sociodemographic characteristics 


\begin{tabular}{|c|c|c|}
\hline \multirow[t]{3}{*}{ Characteristics } & \multicolumn{2}{|c|}{ Sex of the participants } \\
\hline & Males & Females \\
\hline & $\mathrm{n}(\%)$ & $\mathrm{n}(\%)$ \\
\hline \multicolumn{3}{|l|}{ Age(years) } \\
\hline 25- 34 & $2(14.3)$ & $1(9.1)$ \\
\hline $35-44$ & $1(7.1)$ & $1(9.1)$ \\
\hline $45-54$ & $1(7.1)$ & $2(18.2)$ \\
\hline $55-64$ & $5(35.7)$ & $5(45.4)$ \\
\hline$>=65$ & $5(35.7)$ & $2(18.2)$ \\
\hline \multicolumn{3}{|l|}{ Residence } \\
\hline Urban & $1(7.1)$ & $0(0.0)$ \\
\hline Rural & 13(92.9) & $11(100)$ \\
\hline \multicolumn{3}{|l|}{ Marital status } \\
\hline Married & 12(85.7) & $9(81.8)$ \\
\hline Single & $1(7.1)$ & $0(0.0)$ \\
\hline Divorced & $1(7.1)$ & $0(0)$. \\
\hline Widowed & $0(0.0)$ & $2(18.2)$ \\
\hline \multicolumn{3}{|l|}{ Level of education } \\
\hline Unable to read & $8(57.1)$ & $10(90.9)$ \\
\hline Able to read and write & $3(21.4)$ & $1(9.1)$ \\
\hline Primary(1 to 8$)$ & $1(7.1)$ & $0(0.0)$ \\
\hline Secondary(9to 12) & $2(14.3)$ & $0.0 \%$ \\
\hline \multicolumn{3}{|l|}{ Religion } \\
\hline Muslim & 12(85.7) & 10(90.9) \\
\hline Orthodox & $2(14.3)$ & $1(9.1)$ \\
\hline \multicolumn{3}{|l|}{ Family size } \\
\hline$<5$ & $5(35.7)$ & $3(27.3)$ \\
\hline$\geq 5$ & $9(64.3)$ & $8(72.7)$ \\
\hline
\end{tabular}




\section{Figures}

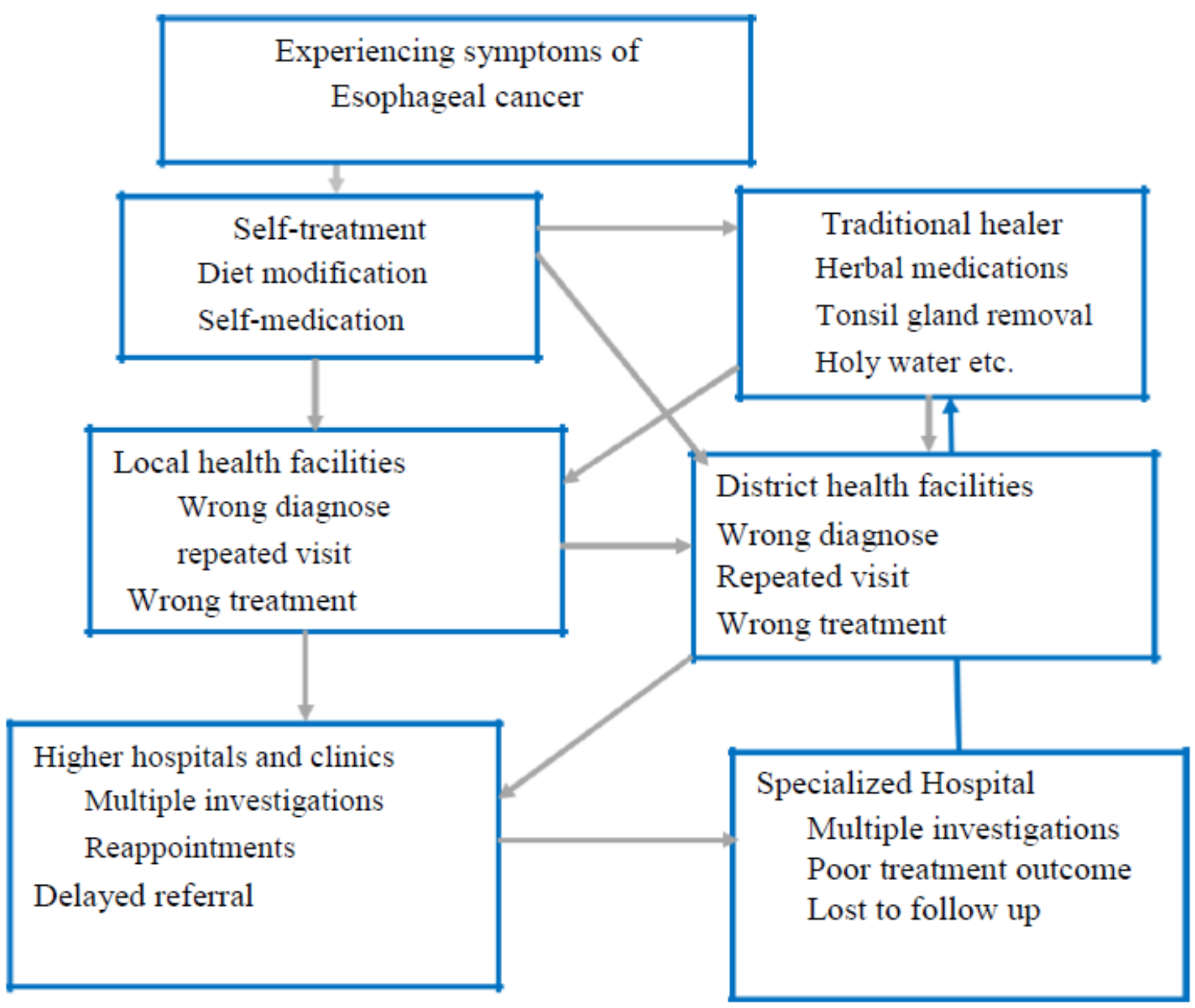

Figure 1

The pathways to seeking treatment of EC patients in Arsi Zone, Ethiopia, 2020

\section{Supplementary Files}

This is a list of supplementary files associated with this preprint. Click to download.

- AdditionalfileFigureS1.pdf

- AdditionalfileTableS1.docx

- AdditionalfileTables2.docx 